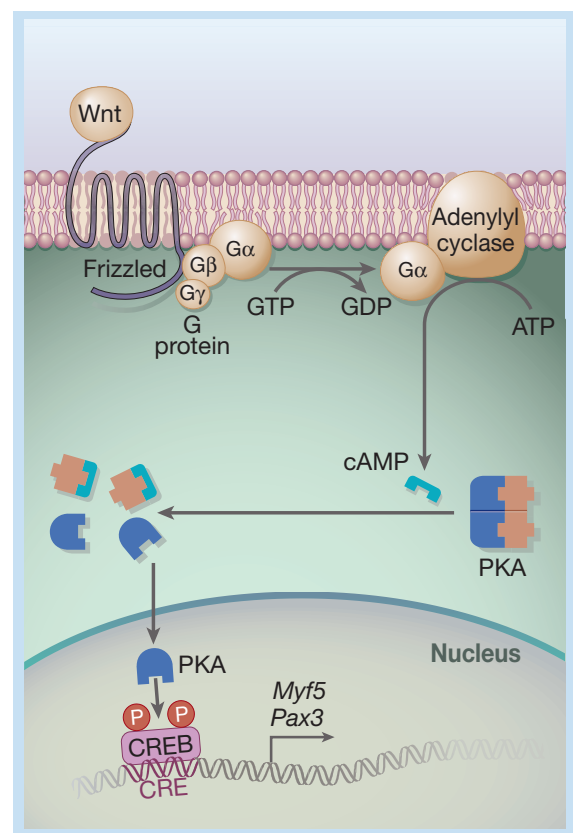

Figure 1 Breaking the mould: a new pathway downstream of the Wnt proteins. Chen et al. ${ }^{1}$ find that muscle development in vertebrates involves the well-known cyclic AMP (cAMP) pathway downstream of Wnts. This proposed pathway begins when a Wnt protein activates its receptor, Frizzled, which is bound to a trimeric G protein. The G protein hydrolyses GTP to GDP, resulting in the release of the G protein's $\alpha$-subunit. This $\mathrm{G} \alpha$ subunit activates adenylyl cyclase, which in turn generates cAMP from ATP; the cAMP binds to protein kinase A (PKA), changing its conformation such that its catalytic subunits are released and move into the nucleus. There they phosphorylate the transcription factor CREB, which binds to genes containing a cAMP-response element (CRE). These genes might include Myf5 and Pax3, markers of muscle development.

regions of the somite destined to form vertebrae was not affected, however.

Chen et al. then used a system in which myogenesis can be activated by culturing muscle precursors with cells expressing Wnt1 or Wnt7A. They found that the induction of myogenesis is accompanied by phosphorylation of CREB. Moreover, in this experimental system, inhibiting PKA or CREB blocks the onset of myogenesis. The authors also found that Wnt signals can increase the activation of genes containing a CREB-responsive element. And genes that control myogenesis, such as Pax3 and Myf5, possess such elements, indicating that they might be regulated by CREB (although it remains to be seen whether they are direct targets of the pathway). Together, these results provide conclusive evidence that the classical cAMP pathway acts downstream of Wnt binding to control myogenesis (Fig. 1).

The discovery of this signalling connection has numerous implications - for myogenesis to begin with. Shh is another major signalling molecule that controls the developmental patterning of somites ${ }^{7}$. During the initial stages of this process, Shh can antagonize Wnt-induced expression of Pax3, a dermomyotome marker. Conversely, Wnt can antagonize Shh-induced expression of Pax1, which marks the precursors of the vertebrae. Given that Shh signalling is inhibited by PKA, PKA activation by Wnts may provide them with a means of antagonizing Shh, to establish the dermomyotome domain precisely.

Paradoxically, however, Shh and Wnt are thought to act synergistically to allow the next tissue involved in muscle development - the myotome - to emerge from the edges of the dermomyotome. This might be explained by the finding that the high PKA activity in the dermomyotome edges falls markedly as dermomyotome cells take up residence in the myotome proper and become more distant from Wnt-producing cells. Such a stepwise coordination of Wnt and Shh signalling could form the basis of their synergism.

Given that the Frizzled proteins are seven-transmembrane-domain receptors, Chen and colleagues' findings ${ }^{1}$ also strengthen the idea that they can act as bona fide GPCRs, signalling through G proteins to cAMP and beyond — an idea that had been in question. Much of our understanding of the pathways activated by Wnts has come from genetic analyses in fruitflies ${ }^{8}$, and components of the cAMP pathway have not been picked up in exhaustive screens of signalling that target a key member of the fruitfly Wnt family called Wingless. Moreover, in fruitflies, the cAMP pathway has been implicated in the control of several behavioural traits ${ }^{9}$, but had not been associated with Wnt-regulated developmental processes. That, too, is changing, however: Katanaev et al. ${ }^{10}$ have just reported a role for $\mathrm{G}$ proteins in Wnt signalling in fruitflies. So it is plausible that Chen and colleagues' findings extend far beyond muscle development, and that a completely new chapter on Wnt signalling needs to be written.

Olivier Pourquié is at the Stowers Institute for

Medical Research, 1000 E 50th Street, Kansas City,

Missouri 64110, USA.

e-mail: olp@stowers-institute.org
. Chen, A. E., Ginty, D. D. \& Fan, C.-M. Nature 433, 317-322 (2005).
2. Vassilatis, D. K. et al. Proc. Natl Acad. Sci. USA 100, 4903-4908 (2003)
3. Shaywitz, A. J. \& Greenberg, M. E. Annu. Rev. Biochem. 68, 821-861 (1999).
4. Barnes, M. R., Duckworth, D. M. \& Beeley, L. J. Trend Pharmacol. Sci. 19, 399-400 (1998).
Gros, J., Scaal, M. \& Marcelle, C. Dev. Cell 6, 875-882 (2004).
6. Tajbakhsh, S. et al. Development 125, 4155-4162 (1998).
Fan, C. M. et al. Cell 81, 457-465 (1995)

8. Moon, R. T., Bowerman, B., Boutros, M. \& Perrimon, N. Science 296, 1644-1666 (2002)

9. Hendricks, J. C. et al. Nature Neurosci. 4, 1108-1115 (2001)

10. Katanaev, V. L., Ponzielli, R., Sémériva, M. \& Tomlinson, A. Cell $120,111-122$ (2005).

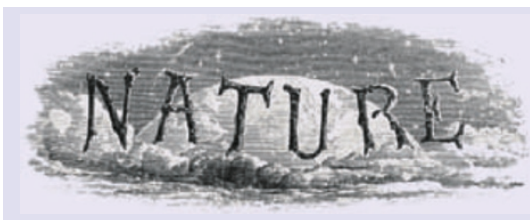

100 YEARS AGO

India. By Colonel Sir Thomas Holdich. With climates varying from the ice-bound deserts of the higher Himalayas and the rain-steeped forests of Tenasserim, to the desolation of Makran... where in one part music is produced by stamping on a piece of wood, and in another has been carried to a refinement which requires sixty-four tones to our octave... where there is found a system of laws so elaborate that the cashier who has confessed to embezzlement may yet succeed in escaping punishment, and a system of government so paternal that it imprisons the husband, whose domestic happiness has been ruined, to prevent his committing the crime of murder; the territories known as British India may be a country for political purposes, but in no proper sense of the word do they constitute a nation... To write a description which, in a book of moderate compass, will convey a clear and fairly proportioned conception, requires a master hand; not to have failed is in itself high praise, but Sir Thomas Holdich has done more than this, he has produced a topographical description of the Indian Empire which... is not only interesting to read, but accurate and well proportioned on the whole. From Nature 19 January 1905.

\section{YEARS AGO}

In a publication entitled "Jean-Sylvain Bailly, Astronomer, Mystic, Revolutionary, 1736-1793"... Edwin Burrows Smith gives an account, including a very comprehensive bibliography and index, of one who was a statesman, astronomer and savant... Born into an essentially artistic milieu, Bailly abandoned the arts to study Newtonian physics, became a respected astronomer and won wide recognition throughout Europe for his research on Jupiter's satellites... The study of Newtonian physics led Bailly to the belief that scientific precision could be extended to other fields of human knowledge, such as history, law, language, etc., and this view led to a breach with the sceptical philosophers who had little confidence in systematic explanations of immaterial or intangible phenomena. As the author of this biography remarks, "Bailly fell victim to the hobgoblin of vraisemblance"; in other words, in cases where truth could not be demonstrated, he was prepared to accept the probable explanation. The French Revolution represented the acid test for Bailly's philosophy... and Bailly's ideas did not survive the test.

From Nature 22 January 1955. 